\title{
Agroforestry Suitability Mapping for the Northwest Provinces of Vietnam ${ }^{\dagger}$
}

\author{
Quyet Manh Vu* and Tri Dan Nguyen \\ Soils and Fertilizers Research Institute, Duc Thang, Bac Tu Liem, Ha Noi 11910, Vietnam; \\ ndtri.gis@gmail.com \\ * Correspondence: vmquyet@gmail.com; Tel.: +84-948-25-1976 \\ + Presented at the Third International Tropical Agriculture Conference (TROPAG 2019), Brisbane, Australia, \\ 11-13 November 2019.
}

Published: 3 April 2020

\begin{abstract}
This study aims to assess the potential development of selected agroforestry options for three provinces in the Northwest of Vietnam. Available spatial data including Land use/land cover maps and forest inventory maps were used as the base maps in combination with supplementary data and field survey to determine the potential agroforestry areas. Soil types, soil depth, soil texture, elevation, slope, temperature and rainfall were used to evaluate the biophysical suitability of ten typical agroforestry options in the study region. For assessing the impact of climate change to agroforestry suitability in the future, temperature and precipitation data extracted from two climate changes scenarios (Representative Concentration Pathway 4.5 and 8.5 in 2046-2065) were used. The results showed that the suitable areas for agroforestry development in Dien Bien, Son La and Yen Bai provinces were 267.74.01 ha, 405,597.96 ha; and 297,995.55 ha, respectively. Changes in temperature and precipitation by 2 climate change scenarios affected significantly to the suitability of Docynia indica + livestock grass, Teak + plum + coffee + grass and Plum + maize + livestock grass options. The map of agroforestry suitability can be served as a useful source in developing and expanding the area of agroforestry in the target provinces, and can be applied for other provinces in the same region in Vietnam.
\end{abstract}

Keywords: agroforestry; climate changes; spatial; suitability; Vietnam

Author Contributions: The analyses and interpretation were done by T.D.N and Q.M.V. The abstract and presentation were written by Q.M.V.

Funding: This research was supported by ACIAR-ICRAF funded project "Developing and promoting marketbased agroforestry and forest rehabilitation options for northwest Viet Nam" (FST/2016/152).

Acknowledgments: This research was carried out by Soils and Fertilizers Research Institute (SFRI), Vietnam. The authors wish to thanks GIS group, Department of Soil Genesis and Classification of SFRI for the supports.

Conflicts of Interest: The authors declare no conflict of interest.

(c) 2020 by the authors. Licensee MDPI, Basel, Switzerland. This article is an open access article distributed under the terms and conditions of the Creative Commons Attribution (CC BY) license (http://creativecommons.org/licenses/by/4.0/). 